Rial Zamudio, Sabela.

Estudiante del Programa de Doctorado en Arte: Producción e Investigación. Universitat Politècnica de Valencia. Departamentos de pintura y escultura.

\title{
Vinculaciones entre arte y terror. La insurgencia vanguardista en la Europa del siglo XX.
}

\section{The link between art and terror. The avant-garde art rebellion in twentieth-century Europe.}

TIPO DE TRABAJO:

Comunicación.

PALABRAS CLAVE:

Terror, arte, terrorismo, sublime, situacionismo.

KEY WORDS:

Terror, art, terrorism, sublime, situacionism.

RESUMEN.

Cuando Karlheinz Stockhausen valoró los atentados del 11S como "la mayor obra de arte jamás realizada", el escándalo provocado fue mayúsculo. Varios de sus conciertos fueron suspendidos y hasta su propia hija pianista anunció que no volvería a actuar bajo el apellido de su padre. Sin embargo, la vinculación entre arte y terror no resultaba ni mucho menos nueva o descabellada. Ya en 1757, cuando el terror aún estaba por surgir, Edmund Burke definía el concepto de lo sublime como una categoría evocadora de lo oscuro y terrorífico. No es de extrañar que fuese precisamente él quien años después acuñase el término terrorismo en referencia al sistema de higienización implantado en Francia durante la Revolución.

Ya en el siglo XX el terrorismo cultural llegó de la mano de la vanguardia artística. Fue a partir de este momento que la destrucción de la moral tradicional, la exaltación de la vida y la lucha contra la monotonía comenzaron a convertirse en reivindicaciones habituales de los movimientos artísticos, que se decantaron por actitudes cada vez más violentas y contundentes como medio para conquistar sus exigencias. Los dadaístas ya habían manifestado su fascinación por los grandes maestros del asesinato cuando Breton visionó el hecho de disparar a ciegas contra la multitud como el acto surrealista más puro. Pero no fue hasta los años sesenta que la influencia de la vanguardia acabó por derivar en notables incursiones en el campo de la verdadera lucha armada. La segunda mitad de este decenio se vio marcada por el estallido de los disturbios y ocupaciones del 68, así como por la progresiva incorporación de la acción directa y el terrorismo político en el seno de una revuelta cultural que no sólo definiría el cambio del paradigma artístico sino también una nueva forma de entender la actividad subversiva.

ABSTRACT.

When Karlheinz Stockhausen rated the 11-S attacks as "the greatest work of art that has ever existed", the resulting public scandal was outstanding. Many of his concerts were cancelled and even his own daughter, who was a pianist at the time, announced that she would never perform under her father's surname again. Nevertheless, the relationship between art and terror was far from new or absurd. In 1757, when the real terror was yet to emerge, Edmund Burke 
defined the concept of sublime as a category evoking darkness and terror. It is not surprising that the term terrorism was coined precisely by this same author years later to make reference to the hygenization systems implemented in France during the Revolution.

Already in the twentieth century, cultural terrorism arrived from the hand of avant-garde art movements. It was from this moment that the destruction of traditional moral, the exaltation of life and the struggle against monotony started to become a usual topic addressed by artists, who chose more aggressive and forceful attitudes to meet their requirements. Dadaists had already expressed their fascination with the great masters of murder when Breton envisioned the act of blindly firing at a crowd as the purest surreal act. However, it was not until the sixties that the influence of avant-garde art led to significant incursions into the realm of true armed conflict. The second half of this decade was marked by the outbreak of riots and occupations in May '68, as well as by the gradual incorporation of direct action and political terrorism in the midst of a cultural revolution, that not only would define the change of the artistic paradigm, but also a new way of understanding subversive action.

\section{CONTENIDO.}

Vinculaciones entre arte y terror. La insurgencia vanguardista en la Europa del siglo XX.

Entre el escándalo y la indignación surgidos a propósito de las ya célebres declaraciones del compositor alemán Karlheinz Stockhausen, quien tuvo la osadía de valorar públicamente como "la mayor obra de arte jamás realizada" los atentados del 11-S -lo que le costó cancelaciones generalizadas de conciertos y hasta el repudio familiar-, volvió a reaparecer la durante un tiempo apartada, aunque casi intrínseca relación entre arte y terror. Lo cierto es que especialmente a partir de este gran atentado, que determinó el inicio de una época marcada por la redefinición de lo que clásicamente se había entendido por terrorismo, proliferó la difusión de una serie de imágenes relacionadas que inauguraron un nuevo modo de narrar el terror y la consecuente necesidad de proponer nuevas conceptualizaciones acerca de las formas de representación del poder y el enemigo. No obstante, la relación esencial entre las ideas de arte y terror, así como la originaria relación entre terrorismo y terrorismo de estado, devenía de mucho tiempo atrás, cuando en el siglo XVIII Edmund Burke se personificó como el precursor de la tradición del horror moderno. Ya en 1957, Burke había definido el concepto de lo sublime como una categoría evocadora de lo oscuro y terrorífico, por lo que, cuando pocos años después acuñó el término terrorista, referido al sistema de la Terreur empleado por el gobierno de Robespierre durante la Revolución Francesa, se indujo que "lo bello había entrado en el campo del terror y el término terrorista se tomaba prestado del terreno de la estética y del arte." ${ }^{1}$ De esta manera, el terror se fundaba como un terrorismo de estado que categóricamente se encontraba vinculado a la idea de sublimidad y por ende a la de arte. En conocimiento de esta tesitura, poco debería ofendernos Stockhausen, que no hacía más que demostrar una cuerda coherencia con los albores fundacionales de la época contemporánea.

Si bien el 11-S había recordado la vinculación entre arte y terror, también trajo consigo consideraciones posteriores acerca de la despenalizada relación entre terrorismo y terrorismo de estado que, como sabemos, se trata de un tema premeditadamente olvidado dentro de cualquier sistema judicial estatal. A día de hoy ningún código penal recoge la posibilidad de que el propio gobierno cometa actos terroristas, tal y como lo había entendido Burke quien, observando temeroso el avance de la revolución en Francia desde la conservadora Inglaterra, inventó el término terrorismo como modo de reflejar la monstruosidad del enemigo bárbaro que reafirmaba a su vez la preponderancia ética del sistema tradicional inglés. En este sentido, aunque se ha hablado de que los propios jacobinos ya se habían autodefinido como terroristas, tratándose Burke de quien introdujo el vocablo en el diccionario, podemos afirmar que este término surgía también como apelativo de deslegitimación para la lucha enemiga. Y este es, sin duda, el rasgo fundamental que la conceptualización del terrorismo mejor y más prolongadamente ha mantenido desde su surgimiento hasta la actualidad: la transmutación interesada del concepto de terrorismo a Terrorismo, es decir, el terrorismo expresado como retrato personificado de un adversario cuya credibilidad se busca eliminar, más que como un modus operandi del que cualquiera puede servirse.

En una sociedad donde el terrorismo que mayoritariamente se acomete no es ni mucho menos el que principalmente se penaliza, la criminalización del gesto disidente viene determinada por el requerimiento sistémico de manutención de una violencia que ya ha sido previamente legitimada por oposición a aquella otra que ansía destruir dado su potencial de amenaza. Ya Guy Debord explicaba la sociedad espectacular como un sistema autónomo basado en su propia perpetuación, cuyo engranaje de auto-representación reiterada buscaba abolir cualquier tipo de posibilidad subversiva. Y aunque el situacionismo no parecía prestar atención -al menos no en demasía- a las complejas técnicas de criminalización esgrimidas contra la lucha antisistema, sí reconocía la negación del derecho a la insurgencia y la insistencia en su eliminación sistemática a manos del poder contra el cual se posicionaba. La negación del derecho a

${ }^{1}$ Rocha, Servando. La facción caníbal. Historia del vandalismo ilustrado. La Felguera. Madrid, 2014 (Primera edición en 2012) p.78-79. 
la subversión lo era a su vez del principio destructor y, en este sentido, la eliminación de la posibilidad revolucionaria arrastraba consigo igualmente la imposibilidad creativa. En un mundo que eliminaba la opción real a disentir, tanto la creación artística como la revuelta no podían manifestarse más allá de la simple quimera, en tanto que requieren de un cierto poder destructivo que permita las tareas de deconstrucción y reconstrucción de los principios socio-políticos y culturales. Fue quizás precisamente por esta razón que el llamamiento a la destrucción y al sabotaje de la sociedad occidental en el siglo XX se antojó destinado a surgir de la mano de la vanguardia artística, que llevó la relación entre arte y terror a su realización literal durante el interludio de las décadas de los sesenta y setenta. Sólo tras barrer y asear ${ }^{2}$ las polvorientas ruinas de la civilización desmembrada, podría erigirse sobre ellas el nuevo espíritu de la humanidad liberada, donde la verdadera creación sería finalmente posible. El ataque pasaba entonces por la difícil tarea de esquivar los mecanismos de separación y recuperación de la acción radical, trascendiendo la distinción entre la política revolucionaria y la crítica cultural, para así superar el arte y realizarlo en la vida. De este modo el reto estribaba en convertir la propia vida en un desafío al sistema a través de la eliminación de todas las categorías, mediaciones y esferas de especialización que conformaban la sociedad impidiendo la verdadera insumisión activa.

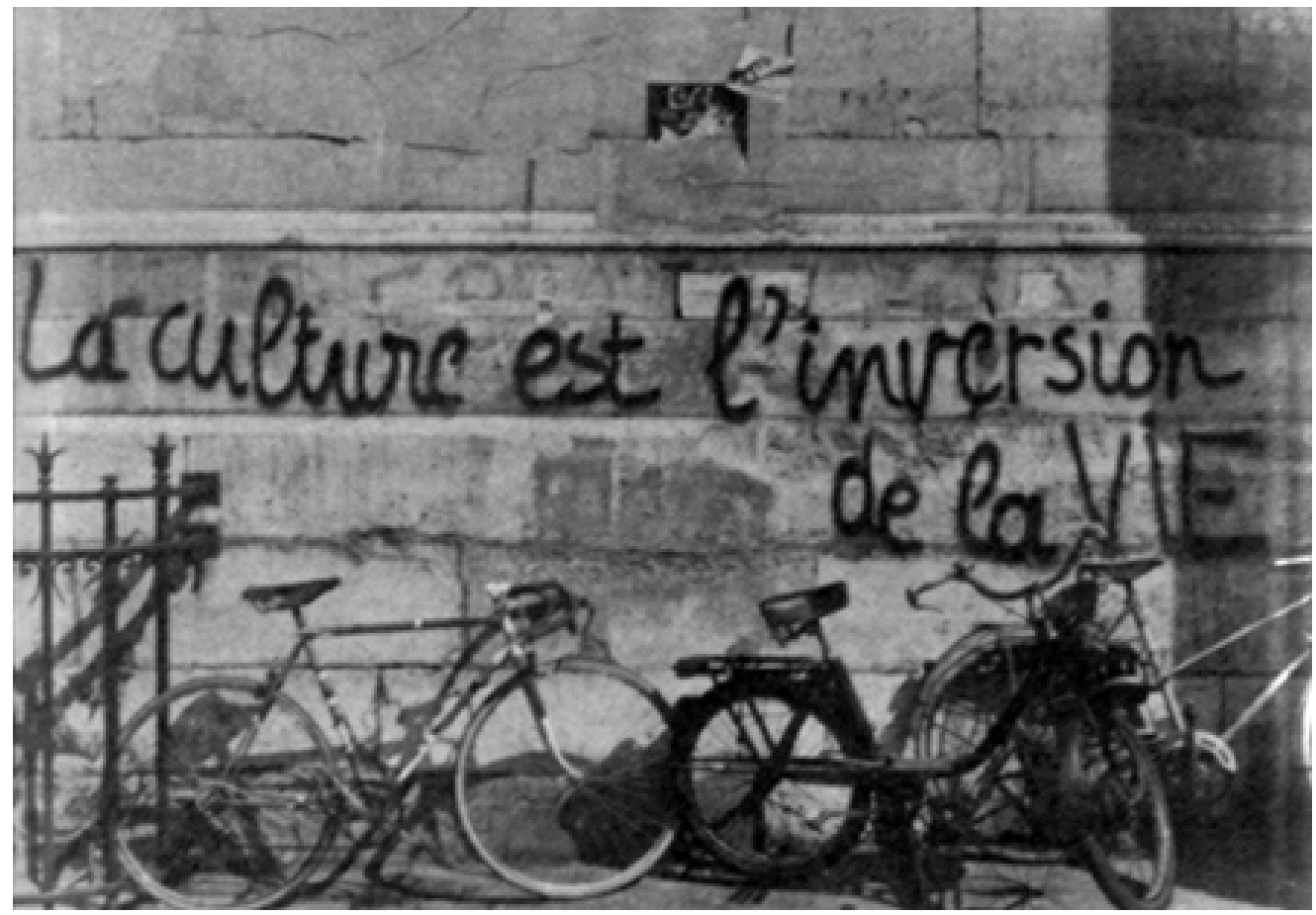

Ilustración 1. La culture est l'inversion de la vie. Grafiti realizado durante el mayo francés. Rue de Vaugirard, París, 1968.

Ya los dadaístas habían manifestado su fascinación por los genios del asesinato cuando Breton visionó el hecho de disparar a ciegas contra la multitud como el acto surrealista más puro o cuando la Internacional Letrista ensalzó a Saint-Just como verdadero maestro de lo terrible, trazando una alusión directa a la conceptualización de lo sublime propuesta por Burke. No obstante, la inclinación de las corrientes de vanguardia hacia los estilos de vida poco ortodoxos, especialmente en sus facetas de marginalidad, criminalidad y revolución, respondía fundamentalmente al interés de estos grupos por rediseñar la cotidianeidad a través de la exaltación de la experiencia vital como leitmotiv revolucionario. Superado el contexto de entreguerras donde se habían enmarcado tanto la provocación dada como el comunismo procesado por los surrealistas, había surgido una nueva generación de jóvenes que vendría a legitimar lo defendido por el letrismo entre 1947 y 1954: el joven insatisfecho entraría ahora en escena como agente fundamental de la revolución política y cultural de la segunda mitad de siglo. Los seguidores de Debord habían encontrado en la cultura del ocio pasivo el gran enemigo a derrotar como modo de purgar el aburrimiento y revolucionar la vida. En este sentido, los aspectos fundamentales del pensamiento desarrollado por la Internacional Situacionista podrían inscribirse en una difusa corriente de hedonismo libertario, resistencia popular y lucha autónoma vinculada tanto a un marxismo heterodoxo como a la tradición vanguardista de agitación

\footnotetext{
${ }^{2}$ Alusión al Manifiesto Dada de 1918 en la cuarta edición de TZARA, TRISTAN. Siete manifiestos Dada. Tusquets Editores. Barcelona, 2012.
} 
pública. Sus integrantes habían observado con espanto como los gestos más radicales del dadaísmo y el surrealismo habían sido saqueados y absorbidos por el sistema capitalista, que los presentaba ahora como una burda e inofensiva representación fácilmente asimilable a la lógica mercantil. Se trataba de un movimiento centrado en un proceso subversivo de deconstrucción, imbuido en la búsqueda de una autonomía individual vinculada a la aspiración de revolucionar la cotidianeidad como máxima política.

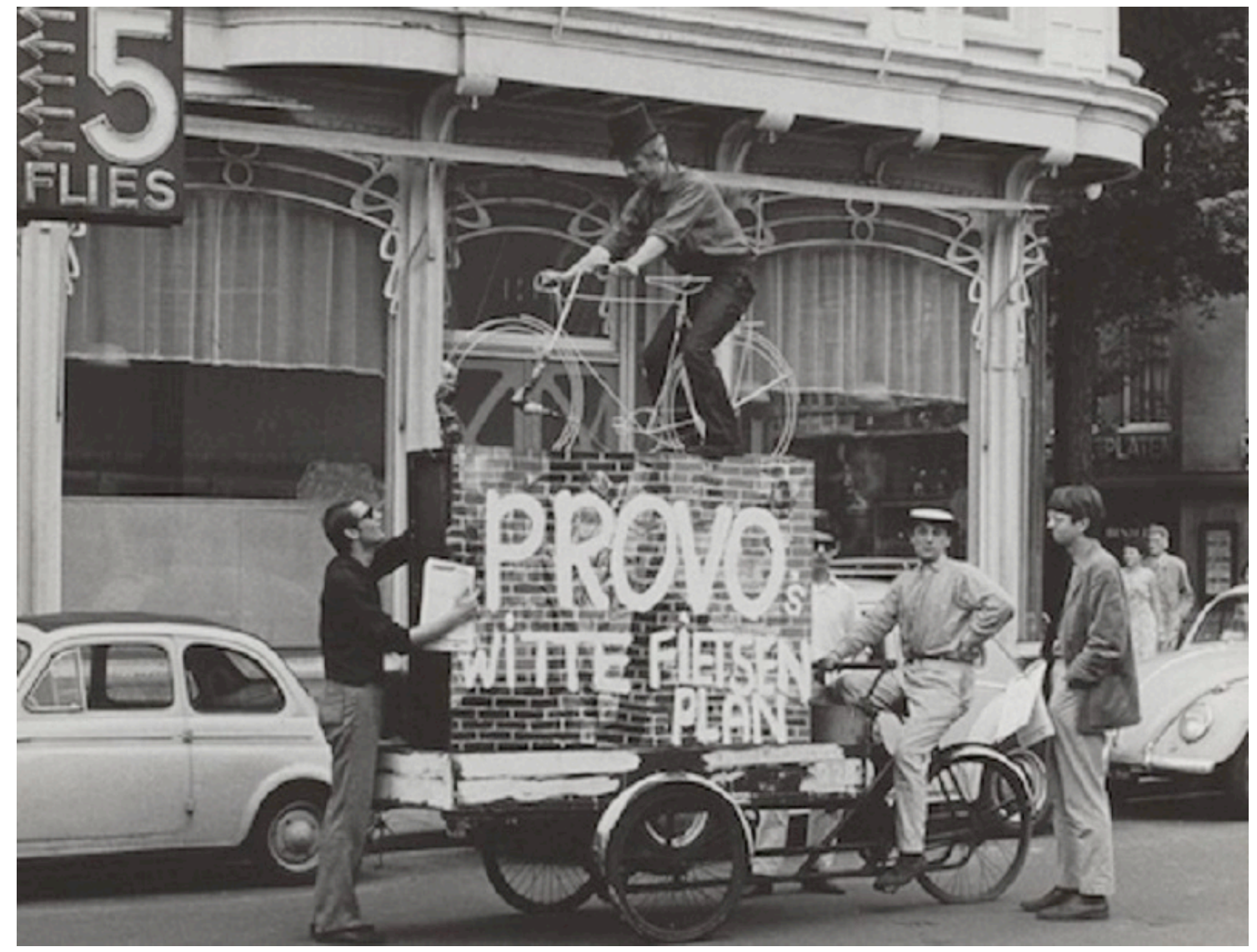

Ilustración 2. Plan de las Bicicletas blancas, dentro de los “planes blancos” provos. Ámsterdam, 1966.

El abandono del arte por parte del especto-situacionismo, como lo llamaría despreciativamente Stewart Home, así como la perdurable influencia del gusto por el alboroto dadaísta junto a la aparición en los años cincuenta de la práctica del happening, llevaría a una nueva generación de jóvenes, madurados entre el movimiento hippie y el hooliganismo, a hacer de su modo de vida alternativo su propia obra de arte. Kommune 1 fue uno de esos experimentos vitales que optaron por fundir el estilo de vida transgresor con una actividad militante que comenzaba a asumir cada vez más estrategias del terror. Desde la formación de la comuna en 1967, sus miembros rechazaron los principios básicos de la organización social a través de una combinación de experimentación vanguardista, sexo comunal y el desarrollo de acciones públicas inspiradas en los actos de contestación social. La primera de ellas fue la denominada como el pudding assassination que tuvo lugar a propósito de la visita a Berlín Occidental del vicepresidente de Estados Unidos, Hubert Humphrey, quien fue recibido con el lanzamiento de pasteles, pintura y bombas de humo. Esta acción no podía dejar de recordar al ataque llevado a cabo en 1964 por Subversive Aktion -precedente directo de Kommune 1- cuyos miembros se presentaron con proyectiles caseros ante la visita a Berlín del Primer Ministro del Congo, Moise Tschombé, o cuando en 1966 los Provos holandeses lanzaron bombas de humo al carruaje de boda de la princesa Beatriz y el príncipe alemán Claus von Amsberg. Esta forma de percibir la protesta a partir del desempeño de una violencia simbólica cercana al juego, que sirvió como experimento de introducción de la acción directa en el seno de la actividad contestataria de corte vanguardista, fue rápidamente condenada por la policía que, tal y como había señalado el provo Grootveld, acabó por convertirse en una especie de co-happener de estas acciones. De hecho, este tipo de apariciones estaban ideadas con el objetivo de hacer que las fuerzas del orden reaccionasen desproporcionadamente para así demostrar los profundos niveles de represión implícitos en el sistema. El hecho de que las fuerzas de seguridad pretendiesen abolir iniciativas como los "planes blancos" provos, que iban más allá del acto de provocación para ocuparse de la introducción de mejoras en el día a día de los vecinos -tales como facilitar bicicletas gratuitas a los viandantes o señalizar viviendas vacías para que quienes las 

propia violencia estructural a través de la criminalización de todo intento constructivo en su contra.

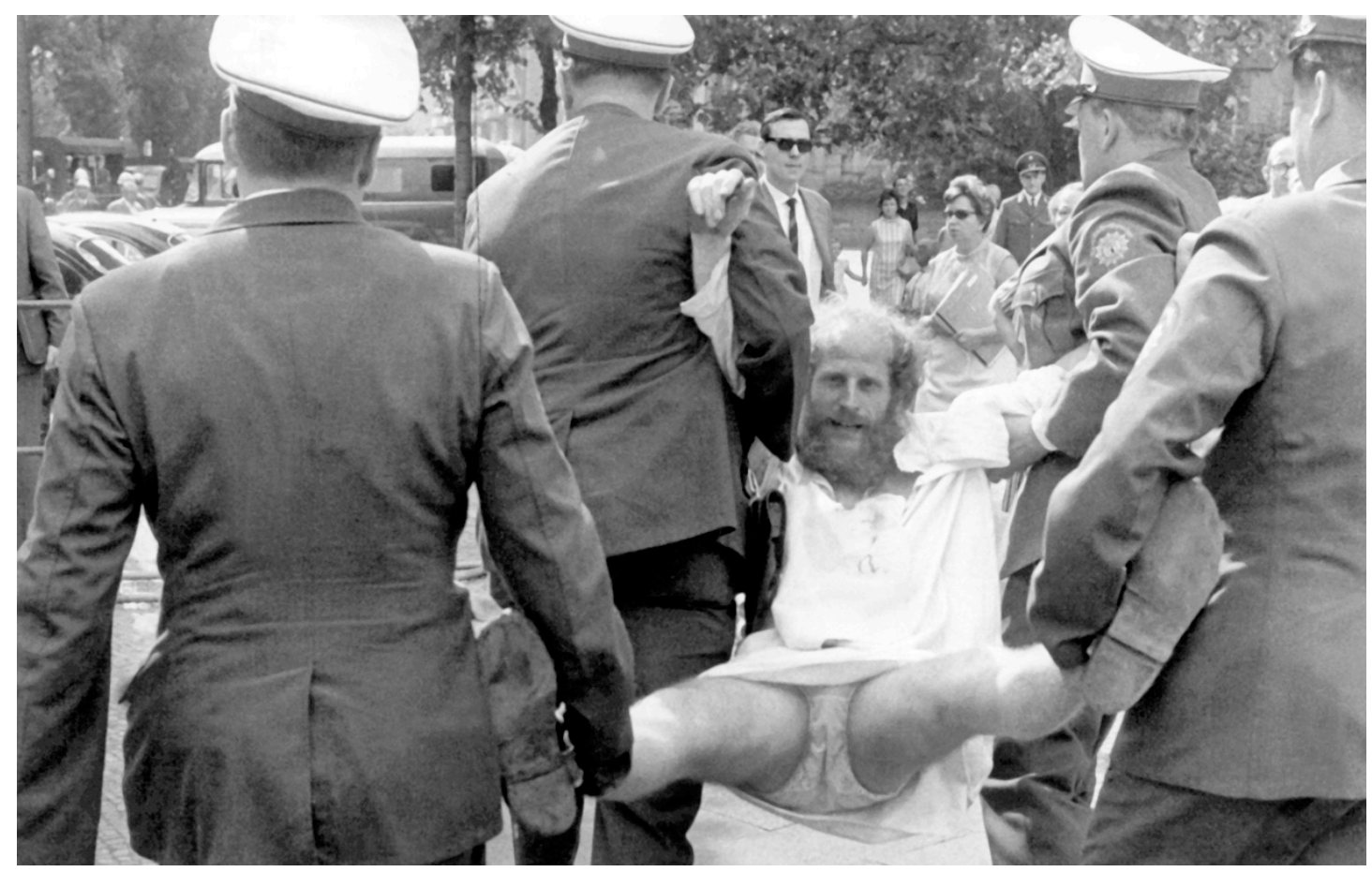

Ilustración 3. Dieter Kunzelmann siendo detenido durante una acción de Kommune 1, 1967.

Si el sistema mercantilista y la imposibilidad de realización personal en el marco organizativo de las instituciones tradicionales suponía el adormilamiento de las potencialidades humanas, entonces la táctica terrorista que buscaba acabar con él debía escapar a la categorización jerárquica y convertir la protesta en una fiesta de violencia y destrucción. "En una sociedad que aniquila la aventura, la única aventura es aniquilar la sociedad" rezaba un lema situacionista. Y con esta filosofía estalló el mayo francés que, aunque surgió como un amotinamiento estudiantil, pronto se extendió hacia los sectores obreros en una crítica absoluta de todos los elementos de la sociedad capitalista, saldada con la prohibición de las manifestaciones callejeras y la ilegalización de los grupos de extrema izquierda por parte de De Gaulle, acabando con una decena de colectivos ilegalizados, la censura de sus publicaciones y la detención de sus líderes. No obstante, el radicalismo procesado por los seguidores del situacionismo no parecía haber cuajado entre los estudiantes, que en París obligaron a los enragés a abandonar el Comité de Ocupaciones de la Soborna, al tiempo que en Londres obviaban las radicales propuestas de King Mob encaminadas a destruir el centro de estudios. "En la escuela, como en todas partes, creemos que la autoridad debe ser atacada y cuestionada a todos los niveles. Pensamos que la educación se debe basar en la cooperación y no en la competición, en trabajar con la gente y no contra ella" ${ }^{3}$ aseguraba King Mob. Para ellos, el alzamiento contra la escuela de arte lo era también contra el statu quo, contra su hipocresía y alienación. Si los estudiantes de arte iban a rebelarse contra el sistema, debían empezar por sus propias escuelas y por el levantamiento contra el mismo arte como producto de consumo. Por esta razón, el grupo aplaudió el intento de asesinato de Andy Warhol a manos de Valerie Solanas y defendió una ocupación del Museo de Arte Contemporáneo de Londres que, sin embargo, nunca llegó a producirse.

La deriva violenta del movimiento vanguardista había empezado a acusarse en Inglaterra. El carácter rudo de la sección inglesa de la Internacional Situacionista, que había abrazado la contracultura y que contaba con alianzas anarquistas en el seno de Black Mask y los Motherfuckers de Nueva York, había provocado el recelo del núcleo francés que acabó por expulsarlos, allanando el camino para la aparición de King Mob en 1968. Su demostrado bagaje conceptual unido a su entrenada experiencia en materia de disturbios y enfrentamientos con la policía los hizo aparecer como un grupo bastante más radical que cualquier otro colectivo de artistas anteriores. A sus ya habituales destrozos de lunas de coches o escaparates de hoteles de lujo, se sumaban acciones como la llevada a cabo en el centro comercial de Selfridges durante las Navidades de 1968, donde un Santa Claus, cuyo delito había estado relacionado

\footnotetext{
${ }^{3}$ King Mob. "Sí, esto es la educación" (Planfleto fijado en la estación de metro de Euston, Londres) en VV.AA. King Mob. Nosotros, el Partido del Diablo. La Felguera, Madrid, 2015 (cuarta edición) p. 166.
} 
con el reparto de unas cínicas postales, fue severamente detenido por la policía ante los ojos de los niños horrorizados. Esta acción, que fue considerada como el mito fundacional del punk, continuaba la tendencia europea de utilizar la presencia policial como elemento enriquecedor dentro de la acción subversiva, evidenciando de esta forma la caracterización gubernamental capitalista como estado policial. Este tipo de acciones, pueden considerarse como ejemplificadoras del paso del terrorismo cultural iniciado por el dadaísmo, al terrorismo urbano de corte vandálico y de incitación al odio que habría definido el carácter de King Mob. Aunque ya grupos anteriores como el Letrismo habían ocupado su tiempo en la realización de acciones prototípicas de las bandas urbanas juveniles -como el saqueo o el robo a las clases pudientes-, aquel tipo de apariciones nocturnas estaba más ligado a una forma de diversión que a la búsqueda consciente de la alteración de la paz y la subversión del orden, requerimiento específico en la definición penal de terrorismo, que denota la importancia del condicionamiento ideológico en la conceptualización jurídica de este delito. No obstante, cabe señalar que el apelativo de terrorismo urbano empleado para definir las acciones de King Mob sólo puede ser expuesto a posteriori, una vez que la paranoia terrorista ha determinado la redefinición hasta la saciedad de este concepto.

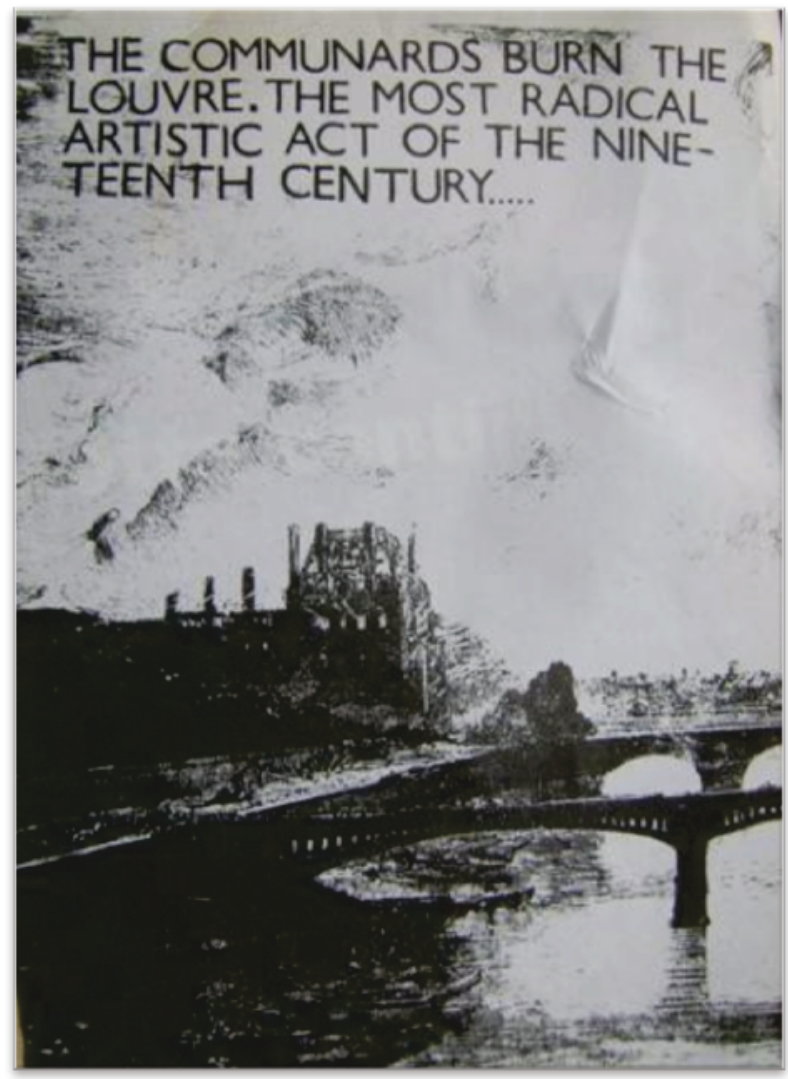

Ilustración 4. The communards burn the Louvre. The most radical artistic act of the nineteenth century. Póster de King Mob, 1968.

El paso efectivo del terrorismo cultural al terrorismo político no se habría efectuado hasta 1970 , cuando una furgoneta de la $B B C^{4}$ que cubría el concurso de Miss Mundo saltó por los aires, siendo esta acción reivindicada por la Angry Brigade, un grupo que se alzaba como la primera forma de guerrilla urbana plenamente inspirada en la vanguardia artística y que conseguía llevar la táctica y la propaganda situacionista al extremo de la rebelión armada. "Cada instante mal pagado en una línea de producción es un crimen violento" ${ }^{5}$ aseguraban. De esta manera, Alemania e Inglaterra parecían transitar sobre caminos paralelos. Los antiguos miembros de Komunne 1, Dieter Kunzelmann, Fritz Teufel o Thorwald Proll habían acabado enrolándose en diferentes organizaciones terroristas. Proll había inaugurado la tendencia en 1968 con su participación en los primeros atentados de la RAF; Teufel se vincularía al grupo Tupamaros de Múnich, provocando media docena de incendios en dicha ciudad, para después unirse a la banda Movimiento 2 de Junio, cercana a la Baader-Meinhof, y ser procesado por el secuestro del candidato a la alcaldía de Berlín, Peter Lorenz; también el alborotador y hedonista Kunzelmann, tras ser entrenado en un campo de Al-Fatah en Jordania, acabaría formando su propio grupo

\footnotetext{
${ }^{4}$ British Broadcasting Corporation.

${ }^{5}$ Angry Brigade, Comunicado 7. Citado en Granés, Carlos. El puño invisible. Arte, revolución y un siglo de cambios culturales. Taurus. Madrid, 2012. p. 325.
} 
terrorista al que denominaría Tupamaros de Berlín Occidental. En el caso de King Mob, aunque no fueron ellos quienes pasaron a desenfundar las armas, si lo hicieron sus silenciosos pupilos que, desde las sombras, habían observado sus movimientos y asumido el papel de descendientes insumisos y contestatarios de un discurso vanguardista que, ante sus dilemas, parecía obligado a teñirse de pólvora. No fue hasta el nacimiento de la Angry Brigade, que la vanguardia se reinterpretó a sí misma, convertida ya de origen en receptáculo de la colisión entre arte y terror, en el cultivo de una ambigüedad táctica que haría tanto gala de la sublimidad burkeana como las delicias del movimiento punk que comenzaba ya a gestarse.

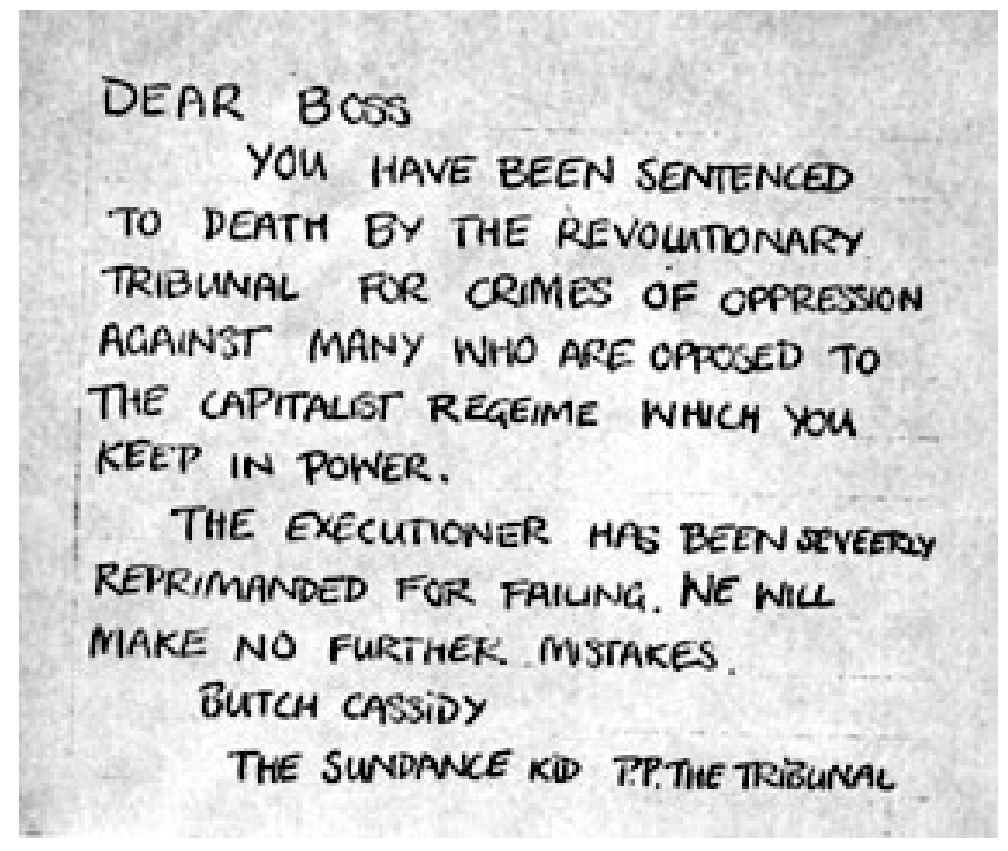

Ilustración 5. Carta enviada al comisario de la Metropolitan Police, John Waldron, por la Angry Brigade en 1970

Para concluir, podemos considerar que el paso del terrorismo cultural al terrorismo político, que supuso la culminación efectiva de la vinculación entre arte y terror conceptualizada ya dos siglos atrás por Burke, tuvo su origen discursivo en el nihilismo dadaísta de principios de siglo, aunque cabe resaltar que fue como consecuencia de la influencia de la teoría situacionista unida a la disconformidad de la nueva juventud con los modos de alienación capitalista, que una serie de experimentos vitales y quehaceres subversivos herederos de la vanguardia artística acabaron adoptando progresivamente los recursos del terror. La sustitución del arte tradicional por la asunción de una teoría crítica que propició un nuevo romanticismo de la revuelta surgía de una interiorizada voluntad política que, tras lo que había sido percibido como un fracaso de la idiosincrasia vanguardista, pareció haber hallado en el empleo de la violencia terrorista la única posibilidad de resolución aún por explorar. Si los conceptos de arte y revolución poseen una cualidad común es su asociación con la idea inherente de creación, ya que proporcionan nuevas maneras de entender el mundo que aproximan lo real a lo soñado o utópico. Sin embargo, ningún proceso creativo puede volverse efectivo sin otro proceso previo de destrucción de las limitaciones mentales, físicas o procedimentales, bajo el imperio de las cuales, ni la revolución ni el arte pueden llegar a aflorar. En este sentido la idea de sublimidad de Burke guarda en sí la fascinación de una aparente relación contradictoria que interpretada desde un lugar y una época donde el terrorismo es fundamentalmente mediatizado, espectacular e hiperreal -es decir, donde, a diferencia de lo sucedido con la vanguardia, el arte ya no se sirve de las estrategias del terror, sino que es el propio terror quien ha asumido ya el sistema de representación del arte-, hace repensar con nostalgia un candor olvidado que, no obstante, los situacionistas volvieron a sentir, aunque sólo fuese como espejismo, cuando en mayo de 1968 observaron recorriendo las calles de París a "Saint-Just in a black leather jacket."

\footnotetext{
${ }^{6}$ Citado en Rocha, Servando. La facción caníbal. Historia del vandalismo ilustrado. La Felguera. Madrid, 2014 (Primera edición en 2012) p.342.
} 


\section{FUENTES REFERENCIALES.}

DEBORD, GUY. Comentarios sobre la sociedad del espectáculo. Barcelona, Anagrama, 1990 (Guy Debord, 1988)

DEBORD, GUY. La sociedad del espectáculo. Valencia, Pre-textos, 2012 (Guy Debord, 1967)

GRANÉS, CARLOS. El puño invisible. Arte, revolución y un siglo de cambios culturales. Madrid, Tauros, 2012 (Carlos Granés, 2011 )

GREGOIRE, ROGER; PERLMAN, FREDY. Worker-Student Action Committees, France May 1968. Detroit, Black \& Red, 1970.

HOME, STEWART. El asalto a la cultura. Corrientes utópicas desde el Letrismo hasta el Class War. Barcelona, Virus editorial, 2004 (Stewart Home, 1988)

PLANT, SADIE. El gesto más radical. La Internacional Situacionista en una época postmoderna. Madrid, Errata Naturae, 2008 (Sadie Plant, 1992)

ROCHA SERVANDO. La facción caníbal. Historia del vandalismo ilustrado. Madrid, La Felguera, 2014 (Servando Rocha, 2012)

ROCHA SERVANDO. Nos estamos acercando. La historia de la Angry Brigade. Madrid, La Felguera, 2008.

SLOTERDIJK, PETER. Temblores de aire. En las fuentes del terror. Valencia, Pre-Textos, 2003. (Suhrkamp Verlag, 2002)

TZARA, TRISTAN. Siete manifiestos Dadá. Barcelona, Tusquets editores, 2012 (Jean-Jacques Pauvert Editeur, 1963)

VANEIGEM, RAOUL. Banalidades de base. Lisboa, Frenesi, 1998 (Raoul Vaneigem, 1963)

VANEIGEM, RAOUL. Tratado del saber vivir para uso de las jóvenes generaciones. Barcelona, Anagrama, 2008 (Raoul Vaneigem, 1967)

VAN DUYN, ROEN. Mensaje de un provo.. Madrid, Editorial Fundamentos, 1975 (Roen Van Duyn, 1969)

VV.AA. Guy Debord y otros. Filosofía para indignados. Textos situacionistas. Barcelona, RBA, 2013.

VV.AA. King Mob. Nosotros, el partido del diablo. Madrid, La Felguera, 2015 (primera edición en 2007)

VV. AA. Sección inglesa de la Internacional Situacionista. La revolución del arte moderno y el moderno arte de la revolución. Logroño, Pepitas de calabaza, 2011 (Sección inglesa I.S., 1967) 